\title{
Affinity purification of eukaryotic 485 initiation complexes
}

\author{
NICOLAS LOCKER, LAURA E. EASTON, and PETER J. LUKAVSKY
}

MRC Laboratory of Molecular Biology, Cambridge CB2 2QH, United Kingdom

\begin{abstract}
In vitro assembly of translation initiation complexes from higher eukaryotes requires purification of ribosomal subunits, eukaryotic initiation factors, and initiator tRNA from natural sources, and therefore yields only limited material for functional and structural studies. Here we describe a robust, affinity chromatography-based purification of eukaryotic $48 \mathrm{~S}$ initiation complexes from rabbit reticulocyte lysate (RRL), which significantly reduces the number of individual purification steps. Hybrid RNA molecules, consisting of either a canonical 5' UTR or an internal ribosome entry site (IRES) RNA followed by a short open reading frame and a streptomycin aptamer sequence, are incubated in RRL to form $48 \mathrm{~S}$ complexes. The assembly reaction is then applied to a dihydrostreptomycin-sepharose column; bound complexes are washed and specifically eluted upon addition of streptomycin. The eluted fractions are further purified by centrifugation through a sucrose density gradient to yield pure $48 \mathrm{~S}$ particles. Using this purification scheme, properly assembled IRES-mediated as well as canonical $48 \mathrm{~S}$ complexes were purified in milligram quantities.
\end{abstract}

Keywords: IRES RNA; affinity chromatography; eukaryotic initiation factors; translation initiation; $48 \mathrm{~S}$ complexes

\section{INTRODUCTION}

In higher eukaryotes, at least two distinct pathways lead to the assembly of a functional $80 \mathrm{~S}$ ribosome containing an initiator tRNA (Met-tRNA ${ }_{i}{ }^{\text {Met}}$ ) base-paired to the AUG start codon of mRNA within the ribosomal P (peptidyl) site (Sachs et al. 1997; Kapp and Lorsch 2004; Merrick 2004). The canonical pathway requires a $5^{\prime}$-capped mRNA and the full complement of eukaryotic initiation factors (eIFs) to coordinate $80 \mathrm{~S}$ assembly. In a first step, eIF4G, eIF4E, eIF4A, and eIF4B mediate binding of the $43 \mathrm{~S}$ particle-which consists of the small 40S ribosomal subunit, the ternary eIF2, GTP, Met-tRNA $_{i}^{\text {Met }}$ complex, eIF3, eIF1A, and eIF1- to the $5^{\prime}$ cap structure. The assembly then scans the $5^{\prime}$ UTR to locate the first AUG start codon and to form a stable $48 \mathrm{~S}$ complex, consisting of the $43 \mathrm{~S}$ components properly assembled at the initiation codon. Subsequently, eIFs are released in a GTPdependent manner, assisted by eIF5 and eIF5B, and the large $60 \mathrm{~S}$ ribosomal subunit joins to form the active $80 \mathrm{~S}$ ribosome. In contrast, some cellular mRNAs and several viral RNAs

Reprint requests to: Peter J. Lukavsky, MRC Laboratory of Molecular Biology, Hills Road, Cambridge CB2 2QH, UK; e-mail: pjl@mrc-lmb.cam. ac.uk; fax: +44-1223-213556

Article published online ahead of print. Article and publication date are at http://www.rnajournal.org/cgi/doi/10.1261/rna.2227906. contain structured $5^{\prime}$ UTRs, termed IRES elements, which mediate initiation without a $5^{\prime}$ cap or scanning and use only a subset of eIFs to form a stable $48 \mathrm{~S}$ complex.

Both initiation pathways have been studied by reconstituting $48 \mathrm{~S}$ complexes in vitro using ribosomal subunits, Met$\mathrm{tRNA}_{\mathrm{i}}^{\mathrm{Met}}$, and eIFs purified from natural sources (Benne and Hershey 1978; Benne et al. 1979; Pestova et al. 1996; Algire et al. 2002). Using this approach, the roles of several eIFs during initiation have been elucidated, and the eIF requirements of several IRES RNAs have been characterized (for reviews, see Hershey and Merrick 2000; Pestova et al. 2001). Recently, an affinity-tagging method for the isolation of hepatitis $\mathrm{C}$ virus (HCV) IRES-mediated $48 \mathrm{~S}$ initiation complexes from HeLa cell lysates has been presented as an additional tool to study $48 \mathrm{~S}$ initiation complexes. In brief, RNA hairpin sequences, which form binding sites for the bacteriophage MS2 coat protein, are introduced upstream of the HCV IRES RNA. The hybrid RNA is incubated in the lysate, bound to amylose beads via a maltose-binding protein (MBP)-MS2 fusion protein, eluted with maltose after several washes, and fractionated on sucrose gradients. Using this method, the assembly of HCV IRES-mediated initiation complexes as well as assembly defects of mutant IRES RNAs could be studied (Ji et al. 2004).

Here we present a new affinity purification-based isolation procedure of $48 \mathrm{~S}$ complexes from rabbit reticulocyte lysate (RRL) using the streptomycin-binding RNA aptamer (Bach- 
ler et al. 1999). The purification protocol was established using the HCV IRES RNA tagged at the $3^{\prime}$ end. The initial affinity-based isolation of crude $48 \mathrm{~S}$ complexes is followed by a final cleanup step using sucrose density gradient centrifugation and yields up to $1 \mathrm{mg}$ of pure $48 \mathrm{~S}$ complex from $10 \mathrm{~mL}$ of lysate. Quantitative Western and Northern blot analysis of the $48 \mathrm{~S}$ particles suggested that eIF2 and eIF3 as well as Met$\mathrm{tRNA}_{\mathrm{i}}{ }^{\text {Met }}$ are present in 1:1 stoichiometry with the $40 \mathrm{~S}$ subunit, and toeprinting analysis showed proper assembly of the components at the AUG start codon. To demonstrate the versatility of the purification protocol, we further isolated $48 \mathrm{~S}$ complexes using tagged, $\beta$-globin mRNA (Dmitriev et al. 2003) and two different IRES RNAs from porcine teschovirus type 1 (PTV-1) (Pisarev et al. 2004) and encephalomyocarditis virus (EMCV) (Borovjagin et al. 1991).

\section{RESULTS AND DISCUSSION}

\section{Design of the hybrid RNA for affinity purification of $48 S$ complexes}

We designed hybrid RNA oligonucleotides containing either a canonical 5' UTR or an IRES element followed by $\sim 85 \mathrm{nt}$ of open reading frame (ORF), a unique primer-binding site for toeprinting analysis (Pestova et al. 1996), then a short uracilcytosine linker and the streptomycin aptamer sequence, the so-called StreptoTag (Bachler et al. 1999). We chose this simple affinity tag since it has been used previously to isolate RNA-protein complexes from cellular extracts with high specificity (Bachler et al. 1999). The RNA aptamer comprises $<50 \mathrm{nt}$ and binds dihydrostreptomycin coupled to a sepharose column matrix with micromolar affinity in a magnesiumdependent manner. In principle, the aptamer could therefore be eluted from the column upon addition of EDTA, but this would destabilize ribosomal particles. As an alternative elu- tion method in the presence of magnesium, a buffer that contains streptomycin at a concentration of $10 \mu \mathrm{M}$ can be used. Since eukaryotic ribosomes are naturally resistant to the antibiotic streptomycin (Chernoff et al. 1994), this method should allow elution of $48 \mathrm{~S}$ complexes in the presence of stabilizing amounts of magnesium.

Compared with the previously published MBP-MS2 fusion protein-based HCV IRES $48 \mathrm{~S}$ affinity purification, which used an RNA tag at the $5^{\prime}$ end of the HCV IRES RNA, we attached the StreptoTag at the $3^{\prime}$ end of the RNA. This should allow both the internal ribosome entry and scanning mode of initiation to occur on the tagged RNA oligonucleotides, since they contain a $5^{\prime}$ end sequence that is not blocked by RNA hairpin sequences. In addition, placing the tag at the $3^{\prime}$ end ensures that only full-length RNAs are bound to the affinity column. To minimize interference from the different coding regions with aptamer binding, we placed three UC repeats upstream of the aptamer as a short, presumably flexible linker. The length of the ORF was kept at $\sim 85 \mathrm{nt}$ to ensure proper spacing between the $48 \mathrm{~S}$ particle and the StreptoTag. In addition, this length is ideal to detect inhibition of primer extension by reverse transcriptase (toeprinting) (Pestova et al. 1996), a method commonly used to test proper assembly of ribosomal initiation complexes (Hartz et al. 1988). To perform toeprinting, a primer needs to anneal to the ORF under the native condition within an intact $48 \mathrm{~S}$ complex. Since strong secondary structure within the ORF could interfere with native binding, we engineered a unique, previously described primer site downstream of the individual ORF sequences (Pestova et al. 1996). To facilitate subcloning of several different IRES RNAs, we introduced an XbaI restriction site upstream of the toeprint primer site into the plasmid DNA template, so that individual IRES RNA elements could be subcloned between the HindIII and the XbaI sites (Fig. 1A). For tagged IRES RNAs, the full-length

A

5' Hind III -T7 Promoter- 5' UTR AUG - ORF ( -85 nt)-Xba I- Toeprint primer binding site-(UC) $)_{3}$-linker - Streptomycin aptamer-EcoR I 3

B

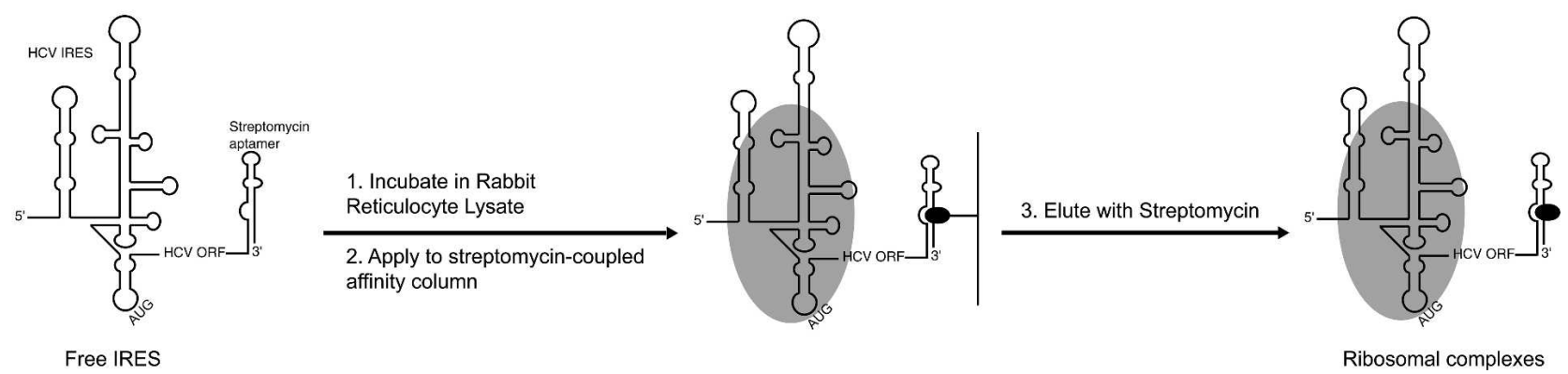

FIGURE 1. Ribosomal $48 \mathrm{~S}$ complex purification. (A) Design of the tagged RNA for affinity purification and analysis of initiation complexes. (B) Strategy for affinity purification of HCV IRES $48 \mathrm{~S}$ complexes from RRL. 
5' UTR sequence was introduced together with the authentic ORF, since the first nucleotides of the coding sequence can be required for efficient IRES function (Reynolds et al. 1995). The tagged $\beta$-globin mRNA comprised the full-length $5^{\prime}$ UTR with a 5'-GGGAG sequence to allow efficient in vitro transcription using T7 polymerase and $54 \mathrm{nt}$ of the coding sequence (Dmitriev et al. 2003). To introduce a $5^{\prime}$ cap structure, transcription reactions were supplemented with $\mathrm{m}^{7} \mathrm{G}\left(5^{\prime}\right) \operatorname{ppp}\left(5^{\prime}\right) \mathrm{GTP}$ (Nielsen and Shapiro 1986).

\section{Affinity purification of $\mathbf{4 8 S}$ complexes}

Our affinity purification protocol for the isolation of eukaryotic initiation complexes was developed and tested using a tagged HCV IRES RNA (Fig. 1B), which contained the first $426 \mathrm{nt}$ of genomic HCV RNA and was constructed as shown in Figure 1A. RRL was used as source of ribosomal subunits, initiation factors, and Met-tRNA ${ }_{i}^{\text {Met }}$ to assemble ribosomal complexes as previously described (Wilson et al. 2000). Briefly, RRL was treated with puromycin to part the ribosomal subunits and then was incubated in the presence of the nonhydrolyzable GTP analog, GMPPNP, to inhibit ribosomal subunit joining and to ensure a blockage of translation initiation events at the $48 \mathrm{~S}$ stage (Merrick 1979). Then, tagged HCV IRES RNA was introduced to allow initiation complexes to form. After incubation, tagged HCV IRES RNA was bound to dihydrostreptomycin-coupled sepharose resin, washed, and released from the column by competitive elution with streptomycin (Fig. 2A). The elution fraction was then analyzed by native agarose gel electrophoresis and compared with purified ribosomal subunits. As shown in Figure 2B, the elution fraction contains the excess of tagged HCV IRES RNA. In agreement with the HCV IRES-mediated initiation pathway, the presence of binary complex between the small ribosomal subunit and the tagged HCV IRES RNA was also detected (Otto and Puglisi 2004). As expected, the eluted $48 \mathrm{~S}$ particle migrated as a single band between the references of the large and the small ribosomal subunits. To further purify $48 \mathrm{~S}$ complexes, HCV IRES-bound translation initiation complexes were pelleted by centrifugation and then fractionated using sucrose density gradient centrifugation, yielding separation between the free RNA, binary complexes, and $48 \mathrm{~S}$ particles (Fig. 2C). As detected on native agarose gel electrophoresis (Fig. 2D), pure $48 \mathrm{~S}$ complexes were obtained. Following this procedure, an input of $2 \mathrm{mg}$ of tagged HCV IRES RNA and 10 $\mathrm{mL}$ of RRL yields up to $1 \mathrm{mg}$ of $48 \mathrm{~S}$ particle.

A control experiment was run in a similar way using an RNA containing the StreptoTag, the linker, and part of the HCV IRES ORF without a start codon. Only the initial RNA could be eluted from the column, indicating that no unspecific binding occurs to the linker or StreptoTag sequence (data not shown).

In order to block the translation initiation pathway at the $48 \mathrm{~S}$ stage, we used a nonhydrolyzable GTP analog, GMPPNP, which inhibits the ribosomal subunit joining by preventing the
A

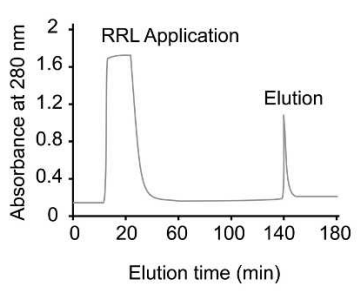

B

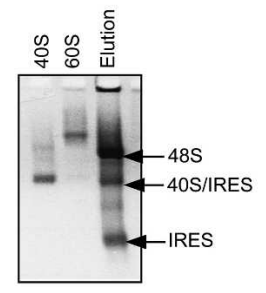

C

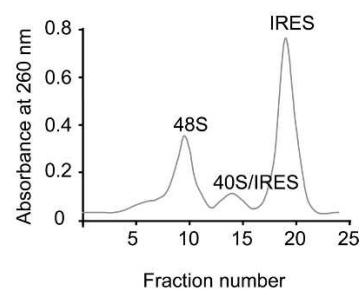

D

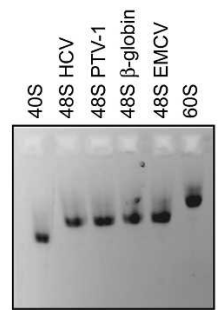

FIGURE 2. HCV IRES ribosomal 48 S complex purification. (A) Profile of streptomycin affinity column. Plots of absorbance at $280 \mathrm{~nm}$ vs. elution time are shown. (B) Analysis of elution fraction composition by $1 \%$ native agarose gel. Lanes are loaded as noted on the gel. Bands corresponding to free RNA, RNA/40S binary, and $48 \mathrm{~S}$ complex are indicated. $(C)$ Sucrose density gradient analysis of translation initiation complexes bound to HCV IRES RNA. Plots of absorbance at 260 $\mathrm{nm}$ vs. sucrose density gradient fractions are shown; peaks corresponding to free RNA, RNA/40S binary, and $48 \mathrm{~S}$ complex are indicated. $(D)$ Analysis of the pooled and concentrated $48 \mathrm{~S}$ fractions for all the assembled particles is shown on $1 \%$ native agarose gel. Lanes are loaded as indicated on the gel.

hydrolysis of eIF2-bound GTP. This blocks the release of eIF2 from $48 \mathrm{~S}$ complexes and therefore the subsequent joining of the $60 \mathrm{~S}$ subunit to form $80 \mathrm{~S}$ ribosomes (Merrick 1979). The purification of $48 \mathrm{~S}$ complexes was performed either with or without GMPPNP. The resulting $48 \mathrm{~S}$ particles were then assayed for the presence of eIF2 using Western blot analysis (Fig. 3A). When GMPPNP was omitted in the $48 \mathrm{~S}$ assembly reaction, only a small amount of eIF $2 \alpha$ could be detected within the $48 \mathrm{~S}$ complexes, because GTP-dependent eIF2 release from the complex was not blocked during the assembly. The same Western blot performed on $48 \mathrm{~S}$ complexes purified in the presence of GMPPNP shows a strong signal for eIF2 $\alpha$, demonstrating efficient blockage of GTP-dependent eIF2 release and thereby translation initiation at the $48 \mathrm{~S}$ stage.

\section{Analysis of the eluted $48 \mathrm{~S}$ particles}

First, we tested the efficiency of the purification protocol by immunoblotting all fractions of the individual purification steps for the presence of eIF2 and eIF3 with antibodies against the eIF $2 \alpha$ or eIF3d subunits, respectively. About $20 \%$ of eIF 2 and $35 \%$ of eIF3 present in the RRL were not incorporated into $48 \mathrm{~S}$ particles and therefore were detected in the flowthrough of the affinity column (Fig. 3B, lanes 1,2). Prolonged incubation time of the tagged HCV IRES RNA in the RRL did not alter the result (data not shown). No eIF2 and eIF3 was detected during the wash of the affinity column, indicating 
A

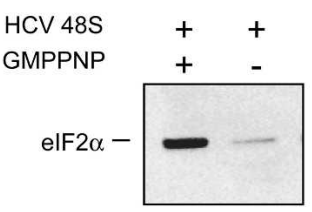

B

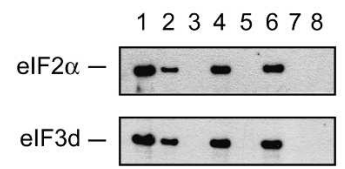

C

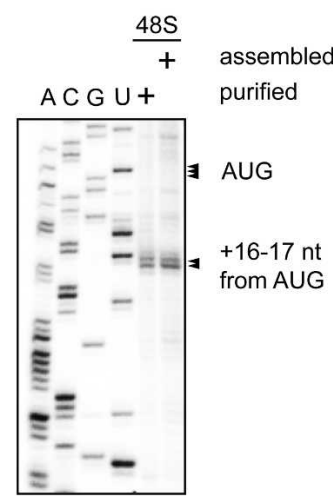

FIGURE 3. Analysis of the composition of HCV IRES $48 \mathrm{~S}$ complexes. (A) Immunoblotting analysis of HCV IRES $48 \mathrm{~S}$ complexes assembled in the absence and the presence of GMPPNP using anti-eIF2 $\alpha$ antibodies. $(B)$ Efficiency of the purification protocol. The presence of eIF2 and eIF3 is followed by immunoblotting through the entire purification. Lanes are loaded as follows: (1) application fraction, (2) flowthrough of the application fraction, (3) wash fractions, (4) elution, (5) supernatant of the centrifugation step, (6) $48 \mathrm{~S}$ peak from the sucrose density gradient, (7) 40S/IRES peak from the gradient, ( 8 ) pooled top fractions from the gradient. (C) Toeprinting assay of both purified and assembled $48 \mathrm{~S} \mathrm{HCV}$ initiation complexes. Arrows denote positions of the initiation AUG codon and toeprinting stops. A dideoxynucleotide sequence generated with the same primer (shown on the left) was run in parallel. The upper part of the gel, which contains additional, previously observed toeprints (Pestova et al. 1998) caused by the processivity of the reverse transcriptase in combination with the particle stability under the assay condition (see Materials and Methods), is omitted for clarity. (D) Detection of Met-tRNA ${ }_{\mathrm{i}}^{\text {Met }}$ within initiation complexes. Northern blot analysis of HCV IRES $48 \mathrm{~S}$ compared with a transcribed $\mathrm{TRNA}_{i}^{\mathrm{Met}}$.

that the particle stayed intact, and $\sim 80 \%$ of the amount of eIF2 and $65 \%$ of the amount of eIF3 initially present in the RRL could be detected in the elution fraction of the affinity column containing the $48 \mathrm{~S}$ complexes (Fig. 3B, lanes 3,4). Also, during the next purification steps the particle stayed intact, since no eIF2 and eIF3 could be detected in the supernatant of the subsequent centrifugation step or in the top fractions of the final sucrose density gradient (Fig. 3B, lanes 5,7,8); only the $48 \mathrm{~S}$ fractions contained the same amount of eIF2 and eIF3 as the initial elution fraction (Fig. 3B, cf. lanes 4 and 6). The presence of both eIF2 and eIF3 in the $48 \mathrm{~S}$ particle, no losses of eIF2 or eIF3 during the individual purification steps, and the migration characteristics of the complex as a single peak in sucrose density gradients as well as a single band on native agarose gels (Fig. 2C,D) therefore strongly suggest that our purification protocol yields pure HCV IRES $48 \mathrm{~S}$ particles containing the expected initiation factors (Pestova et al. 1998).

Assembly of $48 \mathrm{~S}$ complexes at the initiation codon of an mRNA can be assessed using a so-called toeprinting assay, which directly identifies the position of the 40S subunit on the mRNA chain (Hartz et al. 1988). In a $48 \mathrm{~S}$ complex, this arrest of reverse transcription occurs always at the same position 16-18 nt downstream of the adenine of the AUG start codon. Such a toeprint indicates that the start codon is placed in the $\mathrm{P}$ site of the small ribosomal subunit and is base-paired to charged Met-tRNA $\mathrm{A}_{\mathrm{i}}^{\text {Met }}$ (Hartz et al. 1988). $48 \mathrm{~S}$ complexes assembled onto HCV IRES RNA using native Met-tRNA ${ }_{i}^{\text {Met }}$ and purified eIF2, eIF3, and 40S sub-
D

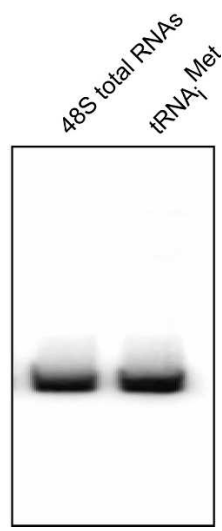

unit yielded stops 16-18 nt downstream the AUG codon (Pestova et al. 1998). Toeprinting analysis of $48 \mathrm{~S}$ complexes assembled onto HCV IRES RNA in GMPPNP-treated RRL yielded stops +16 and +17 nt downstream of the AUG codon (Otto and Puglisi 2004).

Toeprinting was used to assess the proper assembly of the isolated initiation complexes. First, $48 \mathrm{~S}$ complexes were assembled onto tagged HCV IRES RNA in RRL in the presence of GMPPNP. Toeprints characteristic of a properly assembled $48 \mathrm{~S}$ complex could be detected (Fig. 3C). The same toeprinting reaction was also carried out on the affinity-purified particles. The detection of the same stops at positions +16 and $+17 \mathrm{nt}$ downstream of the AUG demonstrated that our purification protocol yielded authentic $48 \mathrm{~S}$ complexes with correct positioning of the AUG start codon within the ribosomal P-site (Fig. 3C).

To further confirm the suggested codon-anticodon base-pairing, we investigated whether Met-tRNA ${ }_{i}^{\text {Met }}$ is present in the purified $48 \mathrm{~S}$ particle. Extraction of total RNA from the $48 \mathrm{~S}$ complex was performed and then compared with an uncharged $\mathrm{RNA}_{\mathrm{i}}{ }^{\mathrm{Met}}$ transcript by Northern blot analysis using a probe complementary to the $3^{\prime}$ end of $\mathrm{tRNA}_{\mathrm{i}}^{\mathrm{Met}}$. As shown in Figure $3 \mathrm{D}$, this experiment confirmed the presence of the $\mathrm{RNA}_{\mathrm{i}}{ }^{\mathrm{Met}}$ in our purified $48 \mathrm{~S}$ complexes, consistent with the toeprinting results.

Our data demonstrate that eIF2, eIF3, and Met-tRNA ${ }_{i}{ }^{\text {Met }}$ are present in the purified $48 \mathrm{~S}$ complexes, and that MettRNA $_{i}{ }^{\text {Met }}$ is base-paired to the AUG start codon in the ribosomal P-site. To further assess the quality of the isolated particles, we performed quantitative Western and Northern blot analysis to also estimate the stoichiometry of the particle components. Serial dilutions of uncharged tRNA $_{\mathrm{i}}{ }^{\text {Met }}$ ranging from 5-25 pMol and total RNA extracted from $15 \mathrm{pMol}$ of HCV $48 \mathrm{~S}$ particle were separated by denaturing PAGE, followed by Northern blot analysis and quantification of band intensities. As shown in Figure 4A, our measurements confirm that Met-tRNA ${ }_{i}{ }^{\text {Met }}$ is present in the $48 \mathrm{~S}$ particle in a 1:1 stoichiometry compared with $40 \mathrm{~S}$ subunits. Since Met-tRNA ${ }_{i}{ }^{\text {Met }}$ association with the $40 \mathrm{~S}$ subunit withstands sucrose density gradient centrifugation, which was used as the final purification step, only in the presence of eIF2 (Unbehaun et al. 2004), the quantitative Northern analysis also strongly suggests that equimolar amounts of eIF2 are present in the particle. Quantitative Western blot analysis using serial dilutions of recombinant eIF $2 \alpha$ and eIF3d over a linear range of $90-450 \mathrm{fMol}$ and 
A
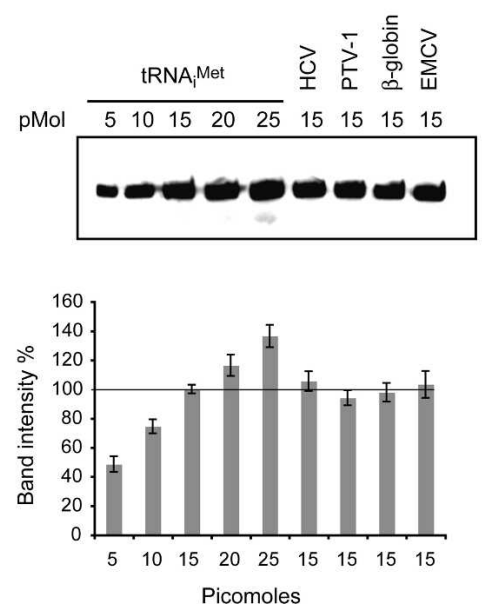

B
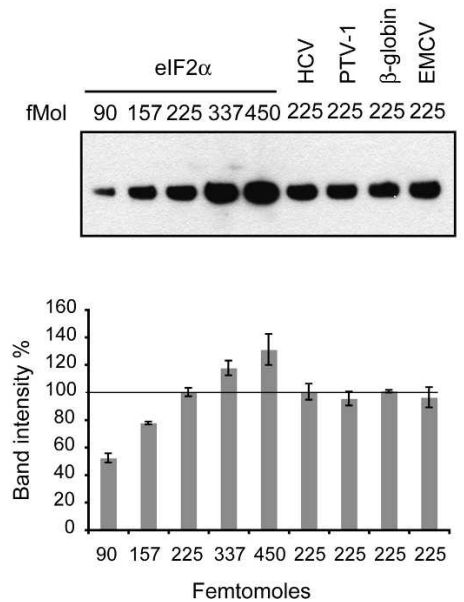

C
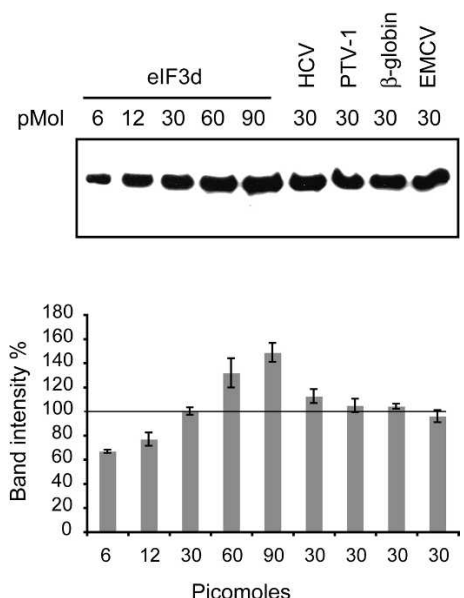

FIGURE 4. Quantitative analysis of $48 \mathrm{~S}$ complexes. (A) Quantitative Northern blot analysis of purified $48 \mathrm{~S}$ complexes using a probe specific to tRNA $_{i}^{\text {Met }}$. Dilutions of transcribed tRNA ${ }_{i}^{\text {Met }}(5-25 \mathrm{pMol})$ and $15 \mathrm{pMol}$ of purified $48 \mathrm{~S}$ complexes were loaded as indicated and resolved by $8 \%$ PAGE. Band intensities were quantified using ImageQuant software, and relative levels of $\mathrm{tRNA}_{\mathrm{i}}{ }^{\text {Met }}$ were normalized to that of the 15 -pMol tRNA ${ }_{i}^{\text {Met }}$ intensity. A graphical representation of the relative intensities is displayed below. All error bars are standard error of the mean. Using a response curve analysis, the following tRNA ${ }_{\mathrm{i}}^{\text {Met }}$ concentrations within the $48 \mathrm{~S}$ complexes have been determined: $17.3 \pm 1.5 \mathrm{pMol}$ for $\mathrm{HCV}, 14.7 \pm 1.3 \mathrm{pMol}$ for PTV-1, $15.6 \pm 1.5 \mathrm{pMol}$ for $\beta$-globin, and $16.8 \pm 2.1 \mathrm{pMol}$ for EMCV. (B) Quantitative immunoblotting analysis of purified $48 \mathrm{~S}$ complexes using antibodies specific to eIF2 $\alpha$. Dilutions of recombinant eIF2 $\alpha(90-450 \mathrm{fMol})$ and $255 \mathrm{fMol}$ of purified $48 \mathrm{~S}$ complexes were loaded as indicated and resolved by $12 \%$ NuPAGE gel. Band intensities were quantified using ImageQuant software, and relative levels of eIF $2 \alpha$ were normalized to that of the 225 -fMol eIF2 $\alpha$ intensity. A graphical representation of the relative intensities is displayed below. All error bars are standard error of the mean. Using a response curve analysis, the following eIF $2 \alpha$ concentrations within the $48 \mathrm{~S}$ complexes have been determined: $224.8 \pm 16 \mathrm{fMol}$ for HCV, $210.6 \pm 14$ $\mathrm{fMol}$ for PTV-1, 225.4 $\pm 3 \mathrm{fMol}$ for $\beta$-globin, and $213.4 \pm 21 \mathrm{fMol}$ for EMCV. (C) Quantitative immunoblotting analysis of purified $48 \mathrm{~S}$ complexes using antibodies specific to eIF3d. Dilutions of recombinant eIF3d $(6-90 \mathrm{pMol})$ and $30 \mathrm{pMol}$ of purified $48 \mathrm{~S}$ were loaded as indicated and resolved by $12 \%$ SDS-polyacrylamide gels. Band intensities were quantified using ImageQuant software, and relative levels of eIF3d were normalized to that of the 30-pMol eIF3d intensity. A graphical representation of the relative intensities is displayed below. All error bars are standard error of the mean. Using a response curve analysis, the following eIF3d concentrations within the $48 \mathrm{~S}$ complexes have been determined: $38.7 \pm 4.2 \mathrm{pMol}$ for $\mathrm{HCV}, 33.1 \pm 4.0$ pMol for PTV-1, $32.7 \pm 1.5 \mathrm{pMol}$ for $\beta$-globin, and 26,7 $\pm 3.6 \mathrm{pMol}$ for EMCV.

6-90 pMol, respectively, indeed suggested the equimolarity of both eIF2 and eIF3 and the 40S subunits (Fig. 4B,C).

\section{General applicability of the purification protocol}

To further probe the versatility of the purification protocol, we also purified $48 \mathrm{~S}$ complexes assembled onto a tagged PTV-1 IRES RNA. The PTV-1 IRES is one of the shortest picornavirus IRES elements. Unlike other picornavirus IRES elements, there is no polypyrimidine tract $20 \mathrm{nt}$ upstream of the AUG codon, and its activity is not affected by eIF4G cleavage (Kaku et al. 2002), reminiscent of the HCV IRES element. Toeprinting experiments performed on in vitro assembled initiation complexes suggested that PTV-1 IRESmediated $48 \mathrm{~S}$ complexes already form in the presence of only $40 \mathrm{~S}$ subunits, eIF2, and Met-tRNA ${ }_{i}^{\text {Met }}$ (Pisarev et al. 2004). The presence of eIF3 in the complex only seemed to enhance the formation of the 48S-specific toeprint, suggesting that eIF3 might be an essential component of the PTV-1 IRESmediated $48 \mathrm{~S}$ particle. In order to test whether eIF3 is a component of the PTV-1 IRES $48 \mathrm{~S}$ complex, we designed a tagged PTV-1 IRES RNA and assembled and purified initiation complexes using the protocol described above. Quantitative analysis again showed that, as for the tagged HCV IRES
RNA, the $48 \mathrm{~S}$ particle contains Met-tRNA ${ }_{\mathrm{i}}^{\mathrm{Met}}$, eIF2 $\alpha$, and eIF3d in equimolar amounts (Figs. 2D, 4). Our purification protocol is also applicable for IRES RNAs with different eIFrequirements, such as the IRES from the picornavirus EMCV (Jang et al. 1988). In contrast to PTV-1- and HCV IRESmediated initiation, the EMCV IRES also requires the eIF4F complex and ATP-hydrolysis to assemble $48 \mathrm{~S}$ complexes (Pestova et al. 1996). The assembly reaction in RRL using tagged EMCV IRES was therefore supplemented with ATP and the complex was purified as before, yielding homogeneous $48 \mathrm{~S}$ particles (Figs. 2D, 4).

In addition to IRES-driven $48 \mathrm{~S}$ assembly, we also tested whether our protocol is suitable for the assembly and isolation of canonical initiation complexes. Canonical initiation requires scanning of the $5^{\prime}$ UTR, which should be possible with the affinity tag being placed at the $3^{\prime}$ end of the mRNAs. In contrast to IRES-mediated initiation, capdependent initiation requires the full complement of initiation factors (Sachs et al. 1997; Kapp and Lorsch 2004; Merrick 2004). In order to validate our method for mRNAs, which initiate translation through the canonical pathway, we used a tagged $\beta$-globin mRNA to isolate canonical $48 \mathrm{~S}$ complexes. Once again, the $48 \mathrm{~S}$ particle migrates as a single band on native agarose gels and con- 
tains equimolar amounts of Met-tRNA ${ }_{i}^{\text {Met }}$, eIF3d, and eIF2 $\alpha$, demonstrating that our protocol is suitable for purifying $48 \mathrm{~S}$ complexes that require scanning during initiation.

\section{Conclusion and outlook}

We presented a novel, affinity chromatography-based method for the purification of eukaryotic $48 \mathrm{~S}$ initiation complexes from RRL. Both canonical and diverse IRESmediated $48 \mathrm{~S}$ complexes could be purified in a quick, twostep procedure. The proper composition and stoichiometry of the components within the isolated particles was assessed by quantitative Northern and Western blot analysis, respectively. Our method can be used as a biochemical tool to study the initiation factor composition of $48 \mathrm{~S}$ complexes assembled onto different cellular or viral IRES RNAs, as we demonstrated with the HCV, PTV-1, and EMCV IRES RNAs. This could complement approaches that use reconstitution of $48 \mathrm{~S}$ particles from purified components. Isolation of $48 \mathrm{~S}$ particles assembled onto mutant IRES RNAs could be used to study the effect of mutations on proper $48 \mathrm{~S}$ assembly, initiation factor recruitment, or release. In addition, our purification scheme provides an efficient way to isolate milligram quantities of $48 \mathrm{~S}$ complexes, which should benefit structural studies of eukaryotic initiation complexes.

\section{MATERIALS AND METHODS}

\section{Preparation of tagged mRNAs}

Oligodeoxynucleotides were purchased from Operon or Sigma Genosys, desalted and lyophilized in $40-\mathrm{nMol}$ synthesis scale. Standard PCR and cloning techniques were used to create DNA inserts from overlapping primers (Lukavsky and Puglisi 2004). First, the Streptomycin aptamer with an upstream toeprint primer region was prepared using two primers $\left(5^{\prime}\right.$ primer, GAGCTCTAG ACGCCGAGATCAGAAATCCCTCTCTCGGATCGCATTTGGAT TCTGCC; 3' primer, GCTCGAATTCGGATCCGACCGTGGTGC CCGAAGGCAGAAGTCCAATGCGATCC). The resulting PCR product was restriction digested with $\mathrm{XbaI}$ and EcoRI and ligated into pUC18 digested with the same enzymes. The purified vector (Strepto-vector) containing the StreptoTag and toeprint primer sequence was then used to subclone DNA inserts (containing a HindIII site, a T7 RNA polymerase promoter, the appropriate $5^{\prime}$ UTR and coding sequence, and an XbaI site) between the HindIII and XbaI sites. The HCV IRES (GenBank database no. AF271632) insert corresponding to nucleotides $1-426$, the PTV-1 IRES (GenBank database no. AB038528) insert corresponding to nucleotides 3-479, and the $\beta$-globin mRNA (Dmitriev et al. 2003) corresponding to nucleotides 1-107 with an additional 5' GGGAG sequence were prepared from overlapping primers. The resulting PCR products were restriction digested with HindIII and XbaI and ligated into the Strepto-vector digested with the same enzymes. The EMCV IRES insert corresponding to nucleotides 406-930 was amplified by PCR from a plasmid containing nucleotides 1-1740 (a kind gift from Richard Jackson, Cambridge University) using two primers ( $5^{\prime}$ primer $5^{\prime}$-GAGCAAGCTTAATACGACTCACTAT AGCATTCCTAGGGGTCTTTCC-3' ${ }^{\prime}$ 3' primer $5^{\prime}$-CTCGGCGTC TAGAGGTAAAATCCATTACGGTATTGTAGAGC- $\left.3^{\prime}\right)$. The PCR product was restriction digested with HindIII and $\mathrm{XbaI}$, yielding two fragments that were ligated into the Strepto-vector digested with the same enzymes. RNA oligonucleotides were transcribed from the above plasmids linearized with EcoRI (HCV IRES, EMCV IRES) or BamHI (PTV-1 IRES) using established protocols and purified by size-exclusion chromatography as described in Lukavsky and Puglisi (2004). The final RNA oligonucleotides were equilibrated into $10 \mathrm{mM}$ Tris- $\mathrm{HCl}$ ( $\mathrm{pH}$ 7.4) buffer using Centriprep centrifugal devices, concentrated to 0.5-1.0 $\mathrm{A}_{260}$ units per microliter, and stored at $-20^{\circ} \mathrm{C}$. $\beta$-globin RNA was transcribed from the above plasmid linearized with EcoRI; a commercial cap structure analog, $\mathrm{m}^{7} \mathrm{G}\left(5^{\prime}\right) \mathrm{ppp}\left(5^{\prime}\right) \mathrm{G}$ (New England Biolabs) was included in the transcription reaction according to a published protocol (Nielsen and Shapiro 1986) to produce a $5^{\prime}$-capped $\beta$ globin mRNA. The RNA was purified using the RNeasy Mini purification kit (Qiagen), equilibrated into $10 \mathrm{mM}$ Tris- $\mathrm{HCl}(\mathrm{pH}$ 7.4) buffer using Centriprep centrifugal devices, concentrated to 0.5-1.0 $\mathrm{A}_{260}$ units per microliter, and stored at $-20^{\circ} \mathrm{C}$.

\section{Purification of factors and ribosomal subunits}

DNA fragments encoding human eIF2 $\alpha$ and eIF3d were prepared by PCR from cDNA libraries (Clontech) using primers $5^{\prime}$-CCA GGGTAGCCATATGCCGGGTCTAAGTTGTAGATTTTATC- $3^{\prime}$ and 5'-GGTGGTGCTCGAGTCATTAATCTTCAGCTTTGGCTTCCATT TCTTC- ${ }^{\prime}$ for eIF $2 \alpha$ and $5^{\prime}$-CCAGGGTAGCCATATGGCAAAGTT CATGACACCCG- $3^{\prime}$ and $5^{\prime}$-GGTGGTGCTCGAGTCATTAAGTTT CTTCCTCTTCTTCTTCCTC for eIF3d, respectively. PCR products were digested with NdeI and XhoI and inserted into pET28a (Novagen) digested with the same enzymes to yield plasmids encoding $\mathrm{His}_{6}$-eIF2 $\alpha$ and $\mathrm{His}_{6}$-eIF3d. Recombinant $\mathrm{His}_{6}$-eIF2 $\alpha$ was expressed in Rosetta (DE3) cells (Novagen) and purified using HiTrap columns (Amersham) as previously described (Ito and Wagner 2004). Recombinant eIF3d was expressed in Rosetta (DE3) cells (Novagen) and purified under denaturing conditions using HIS-SELECT spin columns (Sigma) according to manufacturer instructions. The purity of both factors was assayed by Western blot analysis using specific antibodies and protein gel analysis, showing no apparent contamination.

Ribosomal subunits were purified according to published procedures (Pestova et al. 1996).

\section{Affinity purification of initiation complexes}

One milliliter $(1 \mathrm{~mL})$ of untreated RRL (Green Hectares) was incubated in $3 \mathrm{~mL}$ of binding buffer $\left(10 \mathrm{mM} \mathrm{MgCl}_{2}, 120 \mathrm{mM}\right.$ $\mathrm{KCl}, 8 \%$ sucrose, $20 \mathrm{mM}$ Tris- $\mathrm{HCl}$ at $\mathrm{pH} 7.6)$ in the presence of $2.5 \mu \mathrm{L}$ of ribonuclease inhibitor (Promega) and half a tablet of protease cocktail inhibitor (EDTA-free, Roche) for $10 \mathrm{~min}$ at $37^{\circ} \mathrm{C}$. After incubation, puromycin was added (final concentration $1 \mathrm{mM}$ ), followed by $10 \mathrm{~min}$ incubation on ice and $10 \mathrm{~min}$ at $37^{\circ} \mathrm{C}$. GMPPNP (Sigma; final concentration $2 \mathrm{mM}$ ) was added for an additional $5 \mathrm{~min}$ at $37^{\circ} \mathrm{C}$. Then, tagged mRNA (final concentration $1 \mu \mathrm{M}$ ) was added, and incubation continued for another 10 $\min$ at $37^{\circ} \mathrm{C}$. In addition, for the assembly of $48 \mathrm{~S}$ complexes onto EMCV and $\beta$-globin mRNA, 1 mM ATP was included to stimulate 
the scanning process. One gram (1 g) of dihydrostreptomycincoupled sepharose 6B (Amersham), prepared as described in Bachler et al. (1999), was equilibrated with binding buffer at $4^{\circ} \mathrm{C}$. Assembly reactions were then slowly loaded onto the column using a peristaltic pump while monitoring absorbance at $280 \mathrm{~nm}$ with a UV Monitor (UV-1, Amersham). A stable baseline was usually reached after washing with 10 column volumes of binding buffer at $4^{\circ} \mathrm{C}$, and then the initiation complexes were eluted at room temperature with binding buffer containing streptomycin (final concentration $10 \mu \mathrm{M}$ ). Complexes were pelleted by centrifugation of the eluted fraction for $16 \mathrm{~h}$ at 45,000 rpm in a Ti90 rotor (Beckman). Ribosomal pellets were resuspended in $20 \mathrm{mM}$ Tris- $\mathrm{HCl}$ (pH 7.6), $100 \mathrm{mM} \mathrm{KOAc,} 200 \mathrm{mM} \mathrm{KCl,} 2.5 \mathrm{mM} \mathrm{MgCl}_{2}$, $2 \mathrm{mM}$ DTT, layered onto a $15 \%-40 \%$ sucrose density gradient in the same buffer, and centrifuged at 22,000 rpm in a Beckman SW2 28 rotor for $16 \mathrm{~h}$ at $4^{\circ} \mathrm{C}$. $48 \mathrm{~S}$ complexes were recovered by fractionating the gradient while monitoring absorbance at $260 \mathrm{~nm}$. Each $1-\mathrm{mL}$ fraction was analyzed on a $1 \%$ agarose gel using Trisborate as running buffer at $4^{\circ} \mathrm{C}$; the clean fractions were pooled, concentrated to a final concentration of $10 \mathrm{~A}_{260}$ units/mL using a YM-50 centricon (Millipore), and stored at $-20^{\circ} \mathrm{C}$. The same protocol was used to purify $48 \mathrm{~S}$ complexes assembled onto PTV$1, \mathrm{EMCV}$, and $\beta$-globin RNAs, except that $\beta$-globin RNA ribosomal complexes were resuspended in $20 \mathrm{mM}$ Tris- $\mathrm{HCl}(\mathrm{pH} 7.6)$, $80 \mathrm{mM} \mathrm{KCl}, 2.5 \mathrm{mM} \mathrm{MgCl}_{2}, 2 \mathrm{mM} \mathrm{DTT}$, and purified through a sucrose gradient prepared in the same buffer conditions. All purified $48 \mathrm{~S}$ complexes were finally analyzed on $1 \%$ native agarose gel.

\section{Western blot analysis}

Proteins from $0.05 \mathrm{~A}_{260}$ units of purified $48 \mathrm{~S}$ particle were resolved by electrophoresis on $4 \%-12 \%$ NuPAGE gels (Invitrogen), transferred to nitrocellulose membranes, and blocked with 5\% dry milk in PBS-Tween $0.2 \%$. Membranes were then probed for eIF2 $\alpha$ with monoclonal antibodies (Abcam, ab5369, dilution 1:2000) and eIF3d with polyclonal antibodies (PTGlab, 10219-1-AP, dilution 1:1000). Primary antibody binding was detected using appropriate HRP-coupled secondary antibodies (Abcam, ab6728 and ab6721, dilution 1:2000) and enhanced chemiluminescence (ECL reagent, Amersham) followed by PhosphorImager analysis.

To follow the presence of eIF2 $\alpha$ and eIF3d through the purification process, equivalent volumes of each fraction (taking the different volumes of fractions into account compared with the initial volume of the assembly reaction) were loaded on a $12 \%$ NuPAGE gel.

\section{Quantitative immunoblotting}

Immunoblotting and detection by chemiluminescence were employed to quantify the level of eIF2 $\alpha$ and eIF3d within $48 \mathrm{~S}$ complexes assembled onto HCV, PTV-1, EMCV, and $\beta$-globin mRNA. The concentrations of purified eIF $2 \alpha$ and eIF3d were determined using extinction coefficients predicted from primary sequence and absorbance measurements at $280 \mathrm{~nm}$ of both proteins denatured in $6 \mathrm{M}$ guanidinium chloride. Serial dilutions of purified eIF2 $\alpha$ and eIF3d were loaded together with a fixed amount of $48 \mathrm{~S}$ complexes with the extinction coefficient of the particle calculated from the three RNA components, the $18 \mathrm{~S}$ rRNA, $\mathrm{tRNA}_{\mathrm{i}}^{\mathrm{Met}}$, and tagged mRNA $\left(1 \mathrm{~A}_{260}\right.$ unit $\left.=43 \mathrm{pMol}\right)$.
Quantitation of eIF2 $\alpha$ and eIF3d over a linear range, 90-450 fMol and 6-90 pMol, was achieved using a standard dilution response curve constructed for each immunoblot. Quantitation of eIF $2 \alpha$ and eIF3d was performed by comparing the band intensities on Hyperfilm ECL (Amersham). The photographic negatives of the immunoblots were scanned to a resolution of $600 \mathrm{dpi}$ in grayscale mode. The scanned images were converted to histograms with ImageQuant software to plot the optical density as a response profile. The total optical density of individual bands was obtained by defining a rectangular area around each band and summing the total OD. To account for irregular baselines, sections of the same sizes as the integrated area were defined under the bands, and their intensity was subtracted. The intensity values were then normalized to that corresponding to a $1: 1$ stoichiometry within the $48 \mathrm{~S}$ complexes and displayed as a percentage referred to this value. The values displayed correspond to the average of three independent experiments.

\section{Primer extension analysis of ribosomal complexes}

For toeprinting analysis of purified $48 \mathrm{~S}$ particles, $0.2 \mathrm{~A}_{260}$ units of complexes were first exchanged into buffer A containing 5\% sucrose, $2 \mathrm{mM}$ DTT, $100 \mathrm{mM}$ KOAc, $20 \mathrm{mM}$ Tris (pH 7.6), 2.5 $\mathrm{mM} \mathrm{Mg}(\mathrm{OAc})_{2}, 0.1 \mathrm{mM}$ GMPPNP, and $0.25 \mathrm{mM}$ spermidine. Extension reactions were then carried out as follows: Ribosomal complexes were incubated for $3 \mathrm{~min}$ at $30^{\circ} \mathrm{C}$ and then $10 \mathrm{~min}$ on ice after adding $5 \mathrm{pmol}$ of primer $5^{\prime}$-GGGATTTCTGATCT CGGCG-3' (Pestova et al. 1996). Then, final concentrations of 1 $\mathrm{mM}$ dNTPs, $5 \mathrm{mM} \mathrm{Mg}(\mathrm{OAc})_{2}, 1 \mu \mathrm{L} \alpha-{ }^{32} \mathrm{P}$ ATP $(3000 \mathrm{Ci} / \mathrm{mmol}$; Amersham), and $0.7 \mathrm{U}$ of avian myeloblastosis virus reverse transcriptase (Promega, $24 \mathrm{U} / \mathrm{mL}$ ) were added and extension was performed for $45 \mathrm{~min}$ at $30^{\circ} \mathrm{C}$. The mixtures were then carefully extracted with phenol to remove proteins. cDNA products were precipitated with ethanol overnight and analyzed on a $6 \%$ sequencing gel. Toeprinting analysis of translation initiation complexes assembled in RRL was performed as described previously (Wilson et al. 2000). Briefly, a master mix containing $15 \mu \mathrm{L}$ RRL and 0.15 $\mu \mathrm{L}$ of ribonuclease inhibitor (Promega) was prepared. GMPPNP was added to a final concentration of $1 \mathrm{mM}$, and the mixtures were incubated for $5 \mathrm{~min}$ at $30^{\circ} \mathrm{C}$, followed by the addition of $0.5 \mu \mathrm{g}$ of mRNA and incubation for another $5 \mathrm{~min}$ at the same temperature. Mixtures were diluted to $40 \mu \mathrm{L}$ in buffer A, and extension reactions were carried out and purified as above. cDNA products of the toeprinting reactions were compared with appropriate dideoxynucleotide sequence ladders performed on the unbound mRNA using the same primer.

\section{Northern blot analysis}

Total RNA was extracted from $0.25 \mathrm{~A}_{260}$ unit of purified $48 \mathrm{~S}$ particle using the acetic acid/ $\mathrm{MgCl}_{2}$ method (Hardy et al. 1969). The extracted RNAs were then separated using a $4 \%$ denaturing polyacrylamide gel together with in vitro transcribed $t \mathrm{RNA}_{i}{ }^{\mathrm{Met}}$ as a positive control (Pestova and Hellen 2001), then transferred to nylon membrane and blotted with ${ }^{32} \mathrm{P}$-labeled probe against the $3^{\prime}$ end of $\mathrm{tRNA}_{\mathrm{i}}{ }^{\mathrm{Met}}$ (5'-GGTAGCAGAGGATGGTTTCGATCC- $3^{\prime}$ ) using ExpressHyb solution (BD Biosciences). The results were visualized using a PhosphoImager. 
To perform quantitative Northern blot analysis, serial dilutions of transcribed and purified $\mathrm{tRNA}_{\mathrm{i}}{ }^{\mathrm{Met}}$ from 25 to $5 \mathrm{pMol}$ were loaded on an $8 \%$ denaturing polyacrylamide gel together with 15 pMol of $48 \mathrm{~S}$ complexes assembled onto HCV, PTV-1, $\beta$-globin, and EMCV RNAs. The intensity of each band was quantified by PhosphorImager analysis using ImageQuant software. To account for irregular baselines, sections of the same sizes as the integrated area were defined under the bands and their intensity subtracted. The intensity values were then normalized to that corresponding to a 1:1 stoichiometry within the $48 \mathrm{~S}$ complexes and displayed as percentage referred to this value. The values displayed correspond to the average of three independent experiments.

\section{ACKNOWLEDGMENTS}

We thank Kiyoshi Nagai for helpful discussions and comments on the manuscript. N.L. is supported through a career development fellowship from MRC.

Received September 13, 2005; accepted December 21, 2005.

\section{REFERENCES}

Algire, M.A., Maag, D., Savio, P., Acker, M.G., Tarun Jr., S.Z., Sachs, A.B., Asano, K., Nielsen, K.H., Olsen, D.S., Phan, L., et al. 2002. Development and characterization of a reconstituted yeast translation initiation system. RNA 8: 382-397.

Bachler, M., Schroeder, R., and von Ahsen, U. 1999. StreptoTag: A novel method for the isolation of RNA-binding proteins. RNA 5: 1509-1516.

Benne, R. and Hershey, J.W. 1978. The mechanism of action of protein synthesis initiation factors from rabbit reticulocytes. J. Biol. Chem. 253: 3078-3087.

Benne, R., Brown-Luedi, M.L., and Hershey, J.W. 1979. Protein synthesis initiation factors from rabbit reticulocytes: Purification, characterization, and radiochemical labeling. Methods Enzymol. 60: 15-35.

Borovjagin, A.V., Ezrokhi, M.V., Rostapshov, V.M., Ugarova, T., Bystrova, T.F., and Shatsky, I.N. 1991. RNA-protein interactions within the internal translation initiation region of encephalomyocarditis virus RNA. Nucleic Acids Res. 19: 4999-5005.

Chernoff, Y.O., Vincent, A., and Liebman, S.W. 1994. Mutations in eukaryotic $18 \mathrm{~S}$ ribosomal RNA affect translational fidelity and resistance to aminoglycoside antibiotics. EMBO J. 13: 906-913.

Dmitriev, S.E., Pisarev, A.V., Rubtsova, M.P., Dunaevsky, Y.E., and Shatsky, I.N. 2003. Conversion of $48 \mathrm{~S}$ translation preinitiation complexes into $80 \mathrm{~S}$ initiation complexes as revealed by toeprinting. FEBS Lett. 533: 99-104.

Hardy, S.J., Kurland, C.G., Voynow, P., and Mora, G. 1969. The ribosomal proteins of Escherichia coli. I. Purification of the $30 \mathrm{~S}$ ribosomal proteins. Biochemistry 8: 2897-2905.

Hartz, D., McPheeters, D.S., Traut, R., and Gold, L. 1988. Extension inhibition analysis of translation initiation complexes. Methods Enzymol. 164: 419-425.

Hershey, J.W.B. and Merrick, W.C. 2000. The pathway and mechansim of initiation of protein synthesis. In Translation control of gene expression (eds. N. Sonenberg et al.), pp. 33-88. Cold Spring Harbor Laboratory Press, Cold Spring Harbor, NY.
Ito, T. and Wagner, G. 2004. Using codon optimization, chaperone co-expression, and rational mutagenesis for production and NMR assignments of human eIF2 $\alpha$. J. Biomol. NMR 28: 357-367.

Jang, S.K., Krausslich, H.G., Nicklin, M.J., Duke, G.M., Palmenberg, A.C., and Wimmer, E. 1988. A segment of the $5^{\prime}$ nontranslated region of encephalomyocarditis virus RNA directs internal entry of ribosomes during in vitro translation. J. Virol. 62: 2636-2643.

Ji, H., Fraser, C.S., Yu, Y., Leary, J., and Doudna, J.A. 2004. Coordinated assembly of human translation initiation complexes by the hepatitis C virus internal ribosome entry site RNA. Proc. Nat. Acad. Sci. 101: 16990-16995.

Kaku, Y., Chard, L.S., Inoue, T., and Belsham, G.J. 2002. Unique characteristics of a picornavirus internal ribosome entry site from the porcine teschovirus-1 talfan. J. Virol. 76: 11721-11728.

Kapp, L.D. and Lorsch, J.R. 2004. The molecular mechanics of eukaryotic translation. Annu. Rev. Biochem. 73: 657-704.

Lukavsky, P.J. and Puglisi, J.D. 2004. Large-scale preparation and purification of polyacrylamide-free RNA oligonucleotides. RNA 10: 889-893.

Merrick, W.C. 1979. Evidence that a single GTP is used in the formation of $80 \mathrm{~S}$ initiation complexes. J. Biol. Chem. 254: 3708-3711.

. 2004. Cap-dependent and cap-independent translation in eukaryotic systems. Gene 332: 1-11

Nielsen, D.A. and Shapiro, D.J. 1986. Preparation of capped RNA transcripts using T7 RNA polymerase. Nucleic Acids Res. 14: 5936.

Otto, G.A. and Puglisi, J.D. 2004. The pathway of HCV IRESmediated translation initiation. Cell 119: 369-380.

Pestova, T.V. and Hellen, C.U. 2001. Preparation and activity of synthetic unmodified mammalian tRNAi(Met) in initiation of translation in vitro. RNA 7: 1496-1505.

Pestova, T.V., Hellen, C.U., and Shatsky, I.N. 1996. Canonical eukaryotic initiation factors determine initiation of translation by internal ribosomal entry. Mol. Cell. Biol. 16: 6859-6869.

Pestova, T.V., Shatsky, I.N., Fletcher, S.P., Jackson, R.J., and Hellen, C.U. 1998. A prokaryotic-like mode of cytoplasmic eukaryotic ribosome binding to the initiation codon during internal translation initiation of hepatitis $\mathrm{C}$ and classical swine fever virus RNAs. Genes \& Dev. 12: 67-83.

Pestova, T.V., Kolupaeva, V.G., Lomakin, I.B., Pilipenko, E.V., Shatsky, I.N., Agol, V.I., and Hellen, C.U. 2001. Molecular mechanisms of translation initiation in eukaryotes. Proc. Nat. Acad. Sci. 98: 7029-7036.

Pisarev, A.V., Chard, L.S., Kaku, Y., Johns, H.L., Shatsky, I.N., and Belsham, G.J. 2004. Functional and structural similarities between the internal ribosome entry sites of hepatitis $C$ virus and porcine teschovirus, a picornavirus. J. Virol. 78: 4487-4497.

Reynolds, J.E., Kaminski, A., Kettinen, H.J., Grace, K., Clarke, B.E., Carroll, A.R., Rowlands, D.J., and Jackson, R.J. 1995. Unique features of internal initiation of hepatitis $\mathrm{C}$ virus RNA translation. EMBO J. 14: 6010-6020.

Sachs, A.B., Sarnow, P., and Hentze, M.W. 1997. Starting at the beginning, middle, and end: Translation initiation in eukaryotes. Cell 89: 831-838.

Unbehaun, A., Borukhov, S.I., Hellen, C.U., and Pestova, T.V. 2004. Release of initiation factors from $48 \mathrm{~S}$ complexes during ribosomal subunit joining and the link between establishment of codonanticodon base-pairing and hydrolysis of eIF2-bound GTP. Genes \& Dev. 18: 3078-3093.

Wilson, J.E., Pestova, T.V., Hellen, C.U., and Sarnow, P. 2000. Initiation of protein synthesis from the A site of the ribosome. Cell 102: 511-520. 

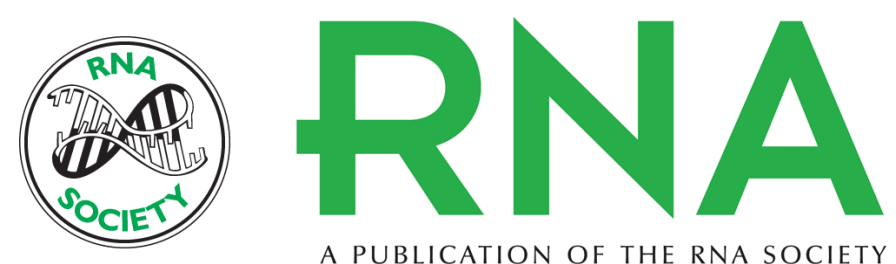

A PUBLICATION OF THE RNA SOCIETY

\title{
Affinity purification of eukaryotic $48 \mathrm{~S}$ initiation complexes
}

\author{
NICOLAS LOCKER, LAURA E. EASTON and PETER J. LUKAVSKY
}

RNA 2006 12: 683-690

$\begin{array}{ll}\text { References } & \begin{array}{l}\text { This article cites } 28 \text { articles, } 14 \text { of which can be accessed free at: } \\ \text { http://rnajournal.cshlp.org/content/12/4/683.full.html\#ref-list-1 }\end{array}\end{array}$

License

Email Alerting Receive free email alerts when new articles cite this article - sign up in the box at the Service top right corner of the article or click here.

To subscribe to RNA go to:

http://rnajournal.cshlp.org/subscriptions 